\title{
Potential emissions savings of lightweight composite aircraft components evaluated through life cycle assessment
}

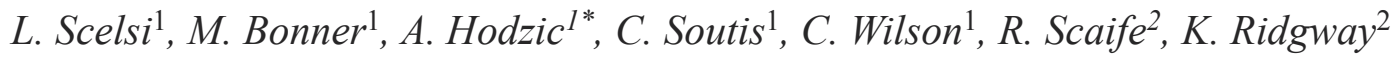 \\ ${ }^{1}$ Aerospace Engineering, Department of Mechanical Engineering, The University of Sheffield, S1 3JD, UK \\ ${ }^{2}$ Advanced Manufacturing Research Centre with Boeing, The University of Sheffield, S60 5TZ, UK
}

\begin{abstract}
A cradle-to-grave life cycle assessment (LCA) of structural aircraft materials has been utilised to assess and compare the total emissions produced during manufacturing, use and disposal of aerospace materials and their selected components. First, a comparison of aluminium, GLARE and carbon fibre reinforced polymer (CFRP) plates was performed to investigate the potential of lightweight composites in reducing aviation emissions. Subsequently, a case study is presented on a tubular component for which more accurate manufacturing data were directly available. A structural steel tube was replaced with a composite tubular component. The analysis has shown that once the composite material is used as a component in the aircraft, there is a cumulative saving of aircraft fuel and emissions, in particular from CFRP structures. The environmental analysis included the long-term use predictions for CFRPs, involving detailed raw materials production, use and operation, and disposal scenarios.
\end{abstract}

Keywords: polymer composites, life cycle assessment, aviation emissions, carbon fibre reinforced polymers (CFRP)

\section{Introduction}

Aviation emissions have come under scrutiny in recent years due to the rapid growth in air transport, which has been increasing at an annual rate of about $5 \%$ throughout the last two decades [1].

The effect of aviation emissions, which consist mainly of carbon dioxide $(71 \%)$, water vapour $(28 \%)$ and nitrogen oxides [2], on the atmosphere is the focus of intense research efforts $[3,4]$. It is widely recognised that emission at high altitudes are more environmentally damaging than those at ground level, due to increased interaction with gases in the atmosphere. A parameter used to quantify the effect of aviation emission is the Radiative Forcing (RF) Index, which is a measure of the impact of an agent on the energy balance of the earth's atmosphere. A positive RF indicates a global warming effect. Aircraft operation involves the emission of (a) directly radiatively active substances (e.g. $\mathrm{CO}_{2}$ or water vapor); (b) chemical species that produce or destroy radiatively active substances (e.g. $\mathrm{NO}_{\mathrm{x}}$, which modifies ozone concentration); and (c) substances that trigger the generation of aerosol particles or lead to changes in natural clouds (e.g. contrails). These emissions and cloud effects modify the chemical and particle microphysical properties of the upper atmosphere, resulting in changes in RF of the earth's climate system, which can potentially lead to climate change impacts and ultimately result in damage and welfare/ecosystem loss [5]. Thus, it is important to analyse the life cycle of aircraft systems and structures in as much detail as possible, in order to understand the long-term impact on the human environment and the earth's ecosystem. Some of these effects - such as the cirrus cloud enhancement due

\footnotetext{
${ }^{*}$ Corresponding author, e-mail: a.hodzic@sheffield.ac.uk
} (c) BME-PT 
to contrails - are still poorly understood, and they are therefore not considered in current environmental models. However, their impact could be substantial and it is therefore necessary to constantly update LCA models, as new or more reliable information becomes available $[6,7]$.

In the civil aviation, implementation of composites and hybrid materials is driven largely by the high cost of aviation fuel and the introduction of legislation setting limits on the emission of greenhouse gases during operation [8]. According to European directive EC 101/2008, from 2012 the aviation sector will be included into the EU ETS emission trading scheme and aircraft operators with flights landing or departing from an $\mathrm{EU}$ airport will be required to buy allowances equal to the $\mathrm{CO}_{2}$ emissions for each flight $[9,10]$. It is widely recognised that the fuel consumption of an aircraft is strongly affected by its total weight and that the fuel used during aircraft operation can be significantly reduced by increasing the proportion of lightweight composites in its structure [11]. On the other hand, disposal of composite parts at their end-of-life is often more problematic than in the case of metals. Composites are not only more costly and energy intensive to produce than metals, but also notoriously difficult to recycle. Whilst the End of life Vehicles (ELVs) Directive 2000/53/EC places a significant burden on the automotive vehicle manufacturers, with recycling and recovery targets of respectively $85 \%$ and $95 \%$ by 2015 , no such legislation applies to the civil aerospace industry. However, there is growing concern in the industry that a similar directive may be introduced [12].

It is therefore clear that the overall environmental benefits of replacing metals with composites are not directly evident, and a full cradle-to-grave life cycle assessment needs to be performed in order to rank different aerospace materials in terms of their environmental impact, as stated by the 'product stewardship principles for the aerospace sector' proposed by the Advisory Council for Aeronautics Research in Europe [12]. This paper aims to establish whether the increase in efficiency gained by using lightweight composite materials is significant enough to justify the additional emissions produced during the manufacturing and disposal stages compared with those of aluminium, and further to investigate after how many hours of flying time do composites and
GLARE become the more environmentally friendly choice. In the aerospace industry, LCAs are being performed to assess various ways of reducing the environmental impact such as new materials, alternative fuels, improved aerodynamic design etc. In particular, the present debate is on the use of composite materials for primary airframe structures instead of the more conventional heavier aluminium. An initial study from Beck et al. [13] provided insights into the different levels of hazardous emissions arising from the manufacturing of $\mathrm{Al}$, CFRP and GLARE hybrid laminates in aerospace industry. However, due to confidentiality reasons and to the difficulty in obtaining data from industry, such study was limited to examining flat plates of equal size made of different materials rather than actual aircraft components. Moreover, no other similar investigations are currently available in the literature.

The present work extend Beck's study by first examining flat plates of Al, GLARE and CFRP taking into account the typical weight savings of these materials, and subsequently presents a more detailed analysis on an actual component, whereby a structural steel tube was replaced with a tubular CFRP component. Although in the case of metals the specific energy $[\mathrm{MJ} / \mathrm{kg}]$ needed to manufacture a component is fairly independent of its shape, size and shaping technology (typically, for aluminium the energy required for shaping the component is very low compared to the energy used to produce the material itself), in the case of composites the curing and shaping processes are simultaneous, and the specific energy requirement for the component is substantially influenced by processing conditions, such as curing temperature and time, type of autoclave used, degree of packing of the autoclave and so on. Those processing conditions can in turn be related to the geometry and dimension of the part, but also to many other factors, which are more specific to the manufacturing site. Therefore, in order to compare the LCA performance of composites and metals in aerospace, it was necessary to examine real size components.

Moreover, due to the complexity of aerospace component design and materials selection, a universal criterion for comparing composites and metal components is not available. As an example, even if the generally recognised design criterion for structural 
parts in the aircraft wing is stiffness, uncertainties about composite materials behaviour (for instance related to anisotropy, damage tolerance and fatigue resistance) often lead design engineers to adopt more conservative safety factors than those used for metallic parts. It can therefore be concluded that the only accurate way to assess both the manufacturing energy and the weight savings of a composite component with respect to its metallic counterpart is to gather industrial data on both components designed to fulfil the same function.

Despite the very specific nature of the LCA analysis for components of such a complex design, examining a critical number of case studies, such as the one presented in this paper, can generate the critical amount of data necessary for understanding and quantifying the potential of the use of composites in emissions savings in the aviation industry.

\section{LCA software and methodology}

SimaPro 7.1 software was used in combination with Ecoinvent database to carry out LCA for aerospace materials (Pré Consultants, NL). The Ecoinvent data v2.0 contains international industrial life cycle inventory data on energy supply, resource extraction, material supply, chemicals, metals, agriculture, waste management services, and transport services. Eco-indicator 99 (E) V2.05 Europe EI 99 E/E was used as a chosen method [7,14]. Such method allows aggregation of different impact categories into a single score value. This is an important aspect, because the success of LCA as a widespread industrial decision tool in the aerospace sector is strongly dependent on the simplicity in interpreting the results of the analysis. ISO 14042 standard (recently replaced by BS EN ISO 14040:2006 [14]) built in SimaPro software) prevents public disclosure of LCA results aggregated into single-score indicators when comparing environmental performance of commercial products. This is mainly due to the subjective nature of the weighting factors used in the calculations. Therefore the method presented in this study should not be used in a commercial context that requires subjective evaluation.

LCA contains inventory analysis and automatically calculates emissions from raw materials production. For the electricity supply, a typical UK energy mix was considered in the calculations ( $41 \%$ natural gas, $33 \%$ coal, $20 \%$ nuclear and smaller propor- tions from other energy sources). Neither environmental impacts associated with the manufacturing of tools, transport and buildings, nor environmental impacts of the labour force required to manufacture the parts are included in the analyses. These aspects have been excluded due to their minor contribution to the goal of the study.

\section{LCA of panels used in aircrafts}

An initial LCA was performed to compare the environmental impact of an aerospace panel when made respectively from aluminium alloy 2024, carbon fibre reinforced epoxy resin (CFRP), and GLARE (glass fibre/Al laminate used by Airbus in A380). These three structural materials have been chosen for comparison due to their relevance, especially aluminium alloy and CFRP. The impact of the manufacture and disposal stages of these materials were analysed with particular interest in the airborne emissions that affect climate change and also the quantity of fossil fuel usage. Further, the in-use phase was taken into account to assess which material is more environmentally friendly over the entire life cycle. A break-even plot was created to assess the amount of flying distance required for the CFRP and GLARE to become the environmentally preferential choice to Al-2024.

The base for comparison between the three materials was their estimated weight in currently designed aircraft structures. From the literature it was found that typical weight savings when using CFRP and GLARE are $20 \%$ and $10 \%$ respectively [15]. Therefore, since Al-2024 panel model weighted $10 \mathrm{~kg}$, the CFRP and GLARE panels were assumed to be 8 and $9 \mathrm{~kg}$ respectively. This choice of criterion for comparison was found to be more relevant to the real-life compared to using panels' dimensions or volumes.

\subsection{Manufacturing and disposal of the panels}

Each panel was obtained from Al-2024 ingots by hot rolling in a four-high rolling mill and the final machining to the required size. The shaping of the Al-2024 ingot into a panel required about $5 \%$ of the energy needed to produce the ingot [16]. It was assumed that the Al-2024 is $100 \%$ recyclable and that the energy saved by recycling as opposed to producing another alloy from scratch is counted as positive emissions. A typical composition of CFRP 
used in this work was 35\% epoxy resin and $65 \%$ carbon fibre by weight [1]. The composite panel was manually laid-up and then cured in an autoclave with a power rating of $26.4 \mathrm{~kW}$ for 6 hours. A typical curing cycle for a $10 \mathrm{~mm}$ thick panel would involve heating at around $0.5^{\circ} \mathrm{C} / \mathrm{min}$ for 2 hours, high temperature curing for 2 hours and cooling at $0.5^{\circ} \mathrm{C} / \mathrm{min}$ for 2 hours. It was estimated that the power used by the heating system during the heating stage would not exceed $60 \%$ of the power rating during the heating stage and this proportion would reduce to $20 \%$ during the rest of the cure cycle. Considering the additional power consumption due to fan $(1.5 \mathrm{~kW})$, compressed air and electronics $(1 \mathrm{~kW})$, the total amount of electricity for the autoclaving process has been determined to be around $68 \mathrm{kWh}$.

GLARE (GLAss-REinforced" Fibre Metal Laminate) is a laminated material consisting of thin $(0.13 \mathrm{~mm})$ layers of aluminium sheet (typically more than $70 \%$ in volume) and unidirectional glass fibre layers embedded in an adhesive system. The layers are laid up and subsequently autoclaved. Due to its relatively limited use in the industry, interest in recycling of the Al layers in the hybrid system has been limited. Moreover, thermal recycling of GLARE might not be environmentally sound, being a very energy intensive process [17]. The Ecoinvent database contains data on the emissions related to the production of GLARE sheets. It was assumed that no substantial emission would arise from manufacturing of the flat panel of the required dimension starting from these sheets. The disposal scenario for both CFRP and GLARE is landfill, as there is no commercial recycling route available at this stage.

Figure 1 shows the global environmental impact using the single score index from Eco-indicator 99 (E). For improved clarity, only impact categories with significant contribution to the overall score are represented. LCA is by nature a comparative analysis, therefore standard Ecoindicator values can be regarded as dimensionless figures. The scale is chosen in such a way that $1 \mathrm{Pt}$ is representative for one thousandth of the yearly environmental load of an average European inhabitant [14].

It can be seen from this graph that the Al-2024 panel is by far the most environmentally friendly choice during the manufacturing stages, the main

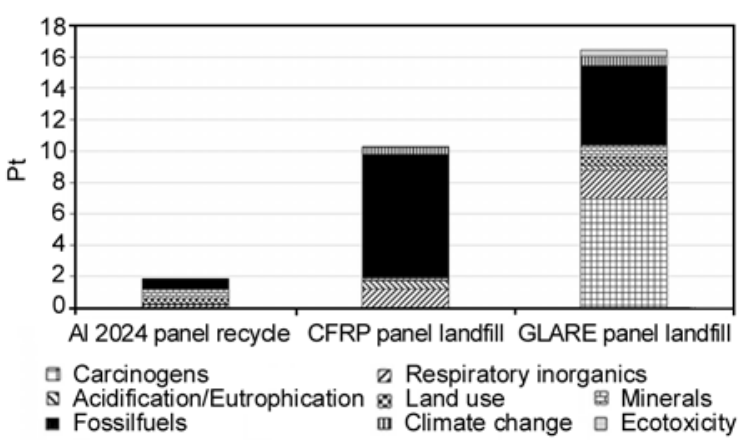

Figure 1. Single score impact results for manufacturing and disposal of Al 2024, CFRP and GLARE panels. $\mathrm{Al} 2024$ is assumed to be recycled at the end of life. CFRP and GLARE are landfilled.

reason being that aluminium is $100 \%$ recyclable. Recycling aluminium requires much less energy than extracting it from its ore and this energy saving is counted as positive emissions. In practice, current material standards for aerospace components do not allow re-using recycled aluminium into new aircraft parts. However, for the purpose of this analysis it was assumed that the recycled aluminum presents almost equal properties to the virgin one and could be reused for high value applications, such as components for trucks, tractors, trailers, railroad cars and buses. The GLARE panel produced the highest environmental impact during this stage of the life cycle with the CFRP producing lower emissions in comparison.

\subsection{In-use}

The objective of this part of the study was to estimate the potential savings of composites over the entire life cycle of the component.

According to the widely-used 'Base of Aircraft Data' (BADA) models [18], fuel consumption for aircraft depends crucially on thrust (Equations (1) and (2)):

Nominal fuel flow $[\mathrm{kg} / \mathrm{s}]=\eta \cdot T$

$\eta[\mathrm{kg} /(\min \cdot \mathrm{kN})]=C_{\mathrm{f} 1}\left(1+\frac{V_{\mathrm{TAS}}}{C_{\mathrm{f} 2}}\right)$

where $T$ is the thrust, $\eta$ the thrust specific fuel consumption, $C_{\mathrm{f} 1}$ and $C_{\mathrm{f} 2}$ thrust specific fuel consumption coefficients, which are dependent on aircraft model, but not on aircraft mass. If, as a first approximation, the thrust-to-weight ratio (i.e. the efficiency factor for total aircraft propulsion) and the 


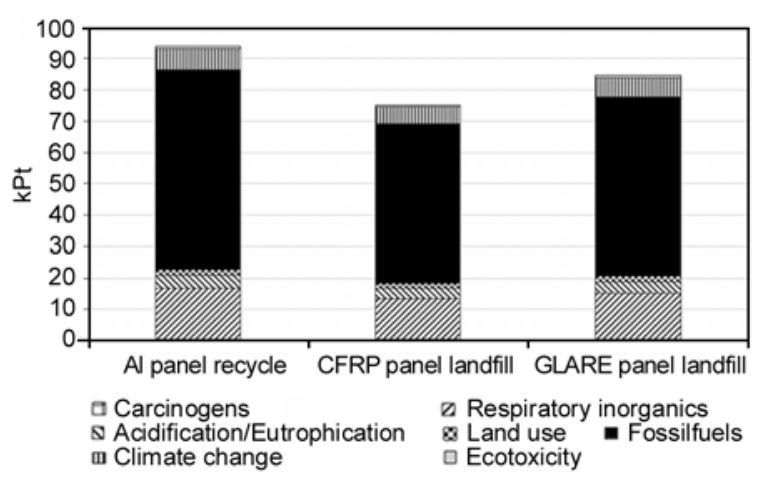

Figure 2. Single score impact results for the entire lifecycle of Al 2024, CFRP and GLARE panels installed on a civil aircraft (freight)

cruise speed are assumed to be mantained constant when replacing metals with composites in a specific aircraft type, fuel consumption can be assumed to be proportional to the total weight of the aircraft.

All panels were assumed to be designed for installation on a civil aircraft with a life time of 30 years and a daily range of $14000 \mathrm{~km}$ [19]. The total distance covered by the aircraft during its lifetime was therefore estimated to be around 150 million $\mathrm{km}$. The panels can be considered as a load that has to be carried by the aircraft during each flight. The functional unit for the transport of the panels, expressed in $[t \cdot k m]$, was calculated for each panel and implemented into a LCA transport model for freight transport.

Figure 2 is a single score impact graph showing the total environmental impact that the panels produce over their entire life cycle.

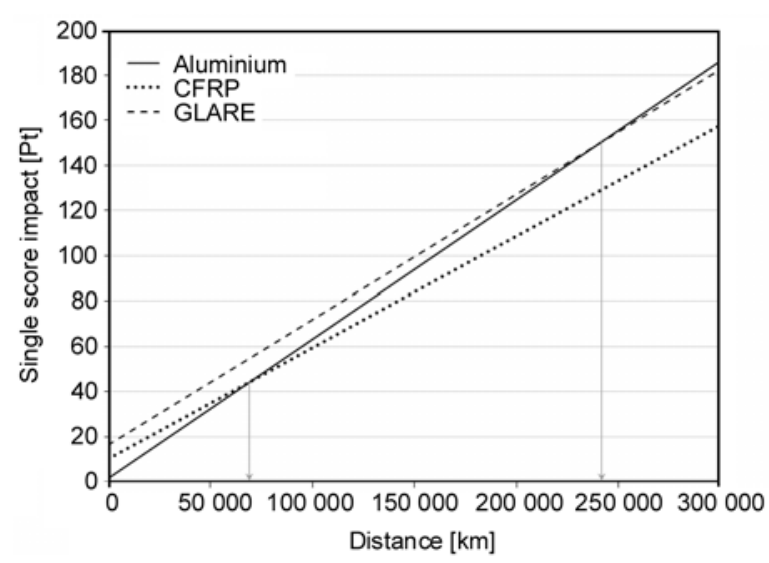

Figure 3. Break even scenarios for single score environmental impact of CFRP and Aluminium plates and GLARE and Aluminium plates. The breakeven distance for CFRP is considerably lower than for GLARE. Method: Eco-indicator 99 (E) V2.05 / Europe EI 99 E/E.

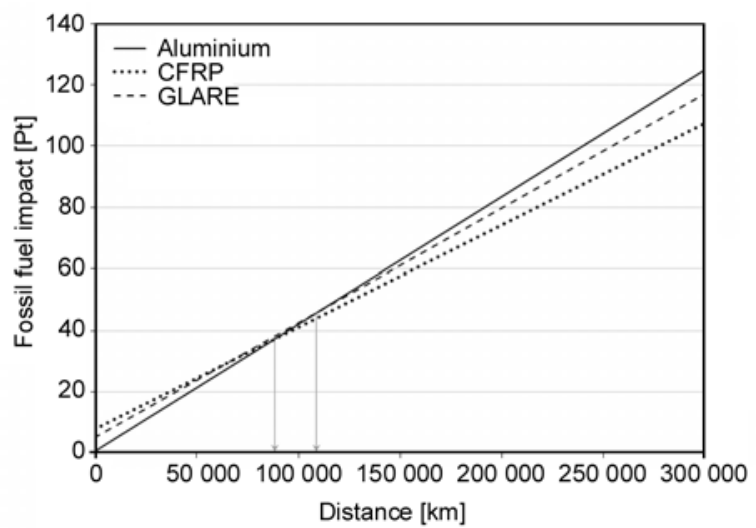

Figure 4. Break even scenarios for fossil fuel depletion impact of CFRP and Aluminium plates and GLARE and Aluminium plates. Method: Ecoindicator 99 (E) V2.05 / Europe EI 99 E/E

From Figure 2 it can be seen that over an entire life cycle the Al-2024 is more environmentally harmful than CFRP and GLARE. It can also be seen that the fossil fuel use impact category dominates the total impact for the three panels. Break-even graphs can also be created, which show the amount of distance that is travelled by the aircraft before the lighter materials become environmentally preferential. Figure 3 shows the break-even plot for single score impact.

From Figure 3 it can be seen that the break-even point for CFRP is approximately $70000 \mathrm{~km}$ and for GLARE panel it is about $240000 \mathrm{~km}$. Break-even plots have also been created with regards to the fossil fuel impact category (Figure 4).

Figures 4 and 5 illustrate that emissions related to climate change are paid back with the fastest turnover, followed by the fossil fuel consumption. These break-even distances can be translated in to times using the speed of the aircraft, which for freight conditions is $750 \mathrm{~km} / \mathrm{h}$ at typical cruise speed. Table 1 shows the break-even distances and times with respect to single score, climate change and fossil fuel consumption.

Table 1. Comparison of break-even times for various impact categories for CFRP and GLARE as replacement for Aluminium 2024 plates

\begin{tabular}{|l|c|c|c|c|}
\hline \multirow{2}{*}{} & \multicolumn{2}{|c|}{ CFRP } & \multicolumn{2}{c|}{ GLARE } \\
\cline { 2 - 5 } & $\begin{array}{c}\text { Distance } \\
{[\mathbf{k m}]}\end{array}$ & $\begin{array}{c}\text { Time } \\
{[\text { hours] }}\end{array}$ & $\begin{array}{c}\text { Distance } \\
{[\mathbf{k m}]}\end{array}$ & $\begin{array}{c}\text { Time } \\
{[\text { hours] }}\end{array}$ \\
\hline Single Score & 70000 & 93 & 240000 & 320 \\
\hline Fossil Fuel & 85000 & 113 & 105000 & 140 \\
\hline Climate Change & 45000 & 60 & 120000 & 160 \\
\hline
\end{tabular}




\section{Case study: LCA of a tubular component}

Having shown the potential benefits of composite materials implemented into aircraft structures, a case study is presented here, following the same methodology and using data for a real component obtained directly from the manufacturer. Unfortunately, due to the strict confidentiality policies in the aviation tier sector, the use of the component cannot be revealed. Despite representing only a few percent of the total weight of an aircraft, steel is still present in aircraft structures and some specific parts made of steel can be replaced with CFRP.

\subsection{Components and manufacturing methods}

The component analysed in this LCA study is a currently utilised commercial application manufactured at Advanced Manufacturing Research Centre with Boeing, Sheffield, UK. The tubular component had approximate length of $660 \mathrm{~mm}$, inner diameter of $670 \mathrm{~mm}$, and wall thickness of $10 \mathrm{~mm}$. The composite contained approximately $75 \%$ hoop fibre, and the resin system was standard epoxy MTM49-3 with the density of $1.78 \mathrm{~g} / \mathrm{cm}^{3}$. Standard Robot Arm power required to manufacture the component using Automatic Fibre Placement (AFP) was $25 \mathrm{~kW}$ over 230 minutes. Autoclave manufacturing method used for curing of the component required $20 \mathrm{~kW}$ over 240 minutes. The equivalent steel tube used in LCA model had the same dimensions with different wall thickness, $5 \mathrm{~mm}$. The manufacturing of the steel tube consisted of seam welded rolled steel sheet.

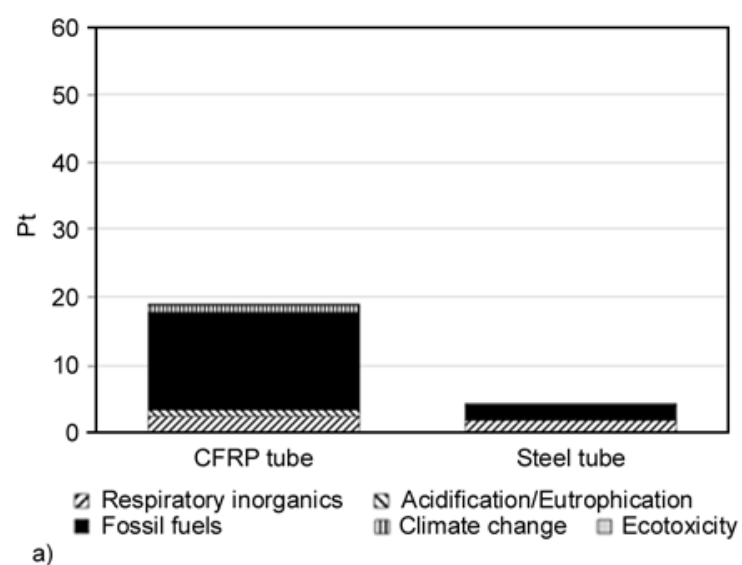

\subsection{LCA results}

For the purpose of the LCA assessment in this particular application, it was of particular importance to compare the initial materials production emissions with the component used in service. Higher initial score for CFRP structure was expected due to the recyclable nature of steel, with the emissions being immediately offset by LCA model. In order to provide data for life-cost analysis of the component, it was important to calculate the break-even points in transport which would effectively provide an estimate of the effectiveness of CFRP in this particular case. Figure 5 shows the cumulative damage to climate involving the single score of emissions and hazardous substances arising from CFRP tube manufacturing and disposal. The analysis of various disposal scenarios did not show any significant variations and thus the incineration was selected to be the representative disposal scenario in this study. According to the LCA model used, incineration had approximately the same impact as landfilling because the emissions from incineration were considered to displace an equivalent amount of coal in a power-station, and, on the other hand, landfilling of composite materials was considered free of any toxic leachate due to the chemical stability of these materials and the efficient landfill system in the UK. It may be concluded that fossil fuel burning from the raw materials processing and component manufacturing contributes the highest level of emissions; considering that, in mass scale production each

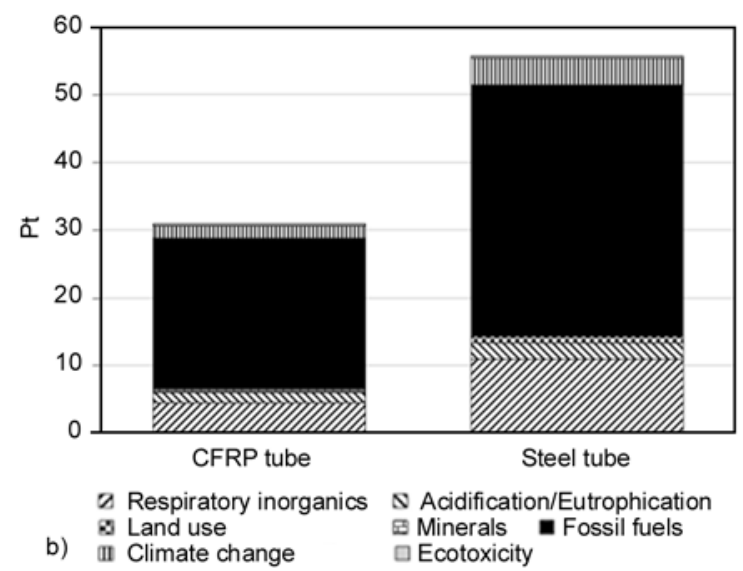

Figure 5. Single impact score calculated for a) CFRP and steel tubes in raw materials production, manufacturing and disposal, and b) after $10000 \mathrm{~km}$ in air transport, showing significant emissions savings due to the implementation of lightweight CFRP structure. Only impact categories with significant contributions to the overall score are represented. 


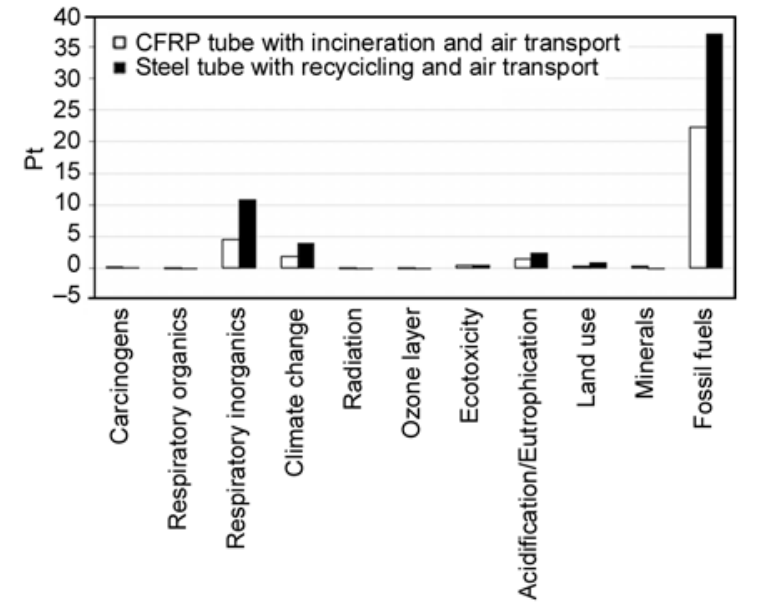

Figure 6. Weighting impact score calculated for CFRP and steel tubes in raw materials production, manufacturing and disposal, and after $10000 \mathrm{~km}$ in air transport. The absolute breakdown of the impact factors shows the most important contributions to pollution and RF index.

parameter will undergo multiplication and thus become more significant. The single impact score improves dramatically for CFRP compared to its predecessor steel component once utilised in the air transport. However, the total impact score still needs to be further assessed in order to evaluate its actual effect onto the environment.

Clearly, the most important factor in this instance is the fossil fuels parameter which takes into account raw production, processing and burning of fossil fuels in the emissions score. Respiratory inorganics and climate change follow as byproducts of all parameters included in the four stages of LCA. Although other parameters are insignificant compared to those three (Figure 6), their values will rise with further operational life of the components and their contribution to the pollution of the ecosystem may still prove to be significant. However, the results show that the implementation of CFRP will significantly improve the overall impact in each LCA parameter over the time in use. In order to observe their relative impacts, the normalisation of the results is shown in Figure 7. Although CFRP shows a significant overall improvement in the emissions score after only one international flight, longer time in operation is required to achieve benefits in the presence of carcinogens, radiation, ozone layer depletion and minerals.

The CFRP and steel tube models were also subjected to three different transport scenarios in order

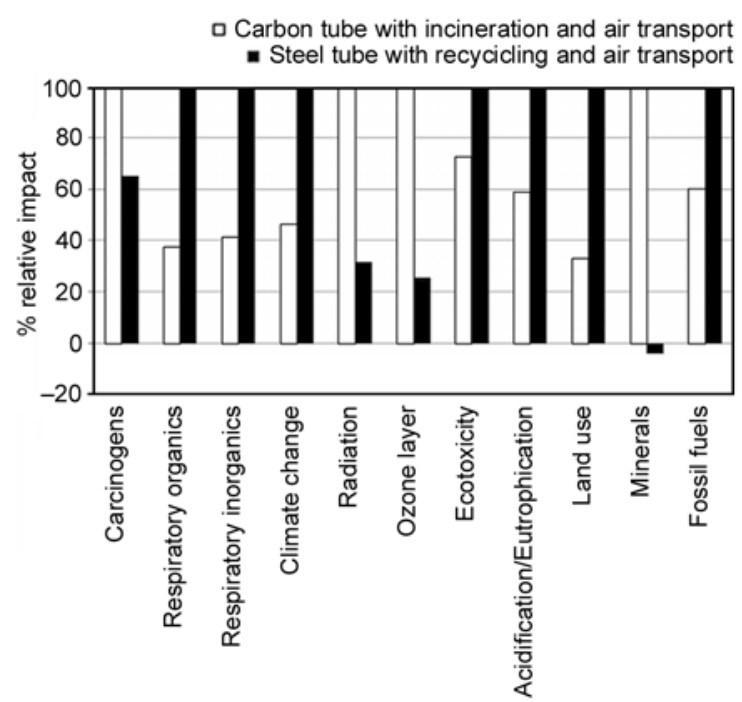

Figure 7. Normalised scores calculated for CFRP and steel tubes in raw materials production, manufacturing and disposal, and after $10000 \mathrm{~km}$ in air transport. Each higher score value is raised to $100 \%$ and the lower shown relative in comparison.

to deteremine the emissions savings once the component is utilised in fuel-saving operation and service. The component was analysed in (i) air transport, cargo aircraft, (ii) road transport, lorry $(7.5 \mathrm{t}<$ weight $<16 \mathrm{t}$ ) and (iii) marine transport, ocean cargo transporter. The purpose of this analysis was to identify the break-even scenario for each transport type, in order to assess i) the efficiency of the component and ii) the efficiency of the transport scenarios, which are important elements of operational life-cycle assessment.

The results are presented in Table 2 and indicate the high level of implemented CFRP component's environmental efficiency in air transport compared to the other transport scenarios. Based on the average cruise speed for transport aircraft $(750 \mathrm{~km} / \mathrm{h})$, motorway driven lorry speed $(80 \mathrm{~km} / \mathrm{h})$ and ocean cargo carrier $(40 \mathrm{~km} / \mathrm{h})$, the above values for break even distances $[\mathrm{km}]$ can be translated into break even times [h] for each type of the transport analysed in this LCA model. Thus, although the marine

Table 2. Comparison of various transport scenarios and their break-even times for steel and CFRP tubes using a single score Ecoindicator 99

\begin{tabular}{|l|c|c|}
\hline Transport scenario & $\begin{array}{c}\text { Break-even distance } \\
{[\mathbf{k m}]}\end{array}$ & $\begin{array}{c}\text { Break-even time } \\
{[\mathbf{h}]}\end{array}$ \\
\hline Air transport & 3600 & 4.8 \\
\hline Road transport & 13600 & 170.0 \\
\hline Marine transport & 373000 & 9325.0 \\
\hline
\end{tabular}


transport appears to be the most effective in terms of emissions savings, weight saving exemplified in the replacement of the steel tube with CFRP tube of the same dimensions will yield the most dramatic emissions saving in air transport.

\section{Conclusions}

A life cycle assessment (LCA) of CFRP, GLARE and Aluminium 2024 plates used as aircraft panels was performed to determine potential emissions savings of lightweight composites over the life of the component. It was shown that, despite being more energy intensive to manufacture and more difficult to dispose of, CFRP and GLARE can lead to substantial decrease in the overall environmental impact when used in aerospace due to the high fuel consumption during air transport. The break-even distances above which CFRP and GLARE start showing a net reduction of environmental damage compared to Aluminium 2024 were respectively 70000 and $240000 \mathrm{~km}$.

Subsequently, a case study was presented on LCA of a CFRP component, which replaced a steel tube, and analysed in several different applications. Real manufacturing data were used and showed in this case a more dramatic reduction in the overall environmental impact by using the composite component. In this case, the break even for replacing a steel component with CFRP was achieved after $3600 \mathrm{~km}$, corresponding to approximately $5 \mathrm{~h}$ of air transport. Lightweight composite structures and hybrid composites produce dramatic positive effect on the total emissions savings when used in the aviation transport. Fossil fuel consumption and the subsequent $\mathrm{CO}_{2}$ emissions are most significantly reduced. Other aspects such as carcinogens and ozone layer depletion require more hours in service to show benefits from the implementation of lightweight structures. Other transport scenarios have shown also to benefit from the implementation of lightweight structures, however they require more hours in operation to realise such environmental benefits, due to their already lower effective emissions compared to the air transport. The areas to further investigate would be the environmental effect of different disposal scenarios of composites in the environment, and their optimised, automatic manufacturing methods.

\section{Acknowledgements}

The authors wish to acknowledge Omega T2 for their financial support of this project.

\section{References}

[1] Macintosh A., Wallace L.: International aviation emissions to 2025: Can emissions be stabilised without restricting demand? Energy Policy, 37, 264-273 (2009). DOI: $10.1016 /$ j.enpol.2008.08.029

[2] Penner J. E., Lister D. H., Griggs D. J., Dokken D. J., McFarland M.: Aviation and the global atmosphere. Cambridge University Press, Cambridge (1999).

[3] Lee D. S., Pitari G., Grewe V., Gierens K., Penner J. E., Petzold A., Prather M. J., Schumann U., Bais A., Berntsen T., Iachetti D., Lim L. L., Sausen R.: Transport impacts on atmosphere and climate: Aviation. Atmospheric Environment, 44, 4678-4734 (2010). DOI: 10.1016/j.atmosenv.2009.06.005

[4] Burkhardt U., Kärcher B., Schumann U.: Global modeling of the contrail and contrail cirrus climate impact. Bulletin of the American Meteorological Society, 91, 479-484 (2010). DOI: 10.1175/2009BAMS2656.1

[5] Lee D. S., Fahey D. W., Forster P. M., Newton P. J., Wit R. C. N., Lim L. L., Owen B., Sausen R.: Aviation and global climate change in the $21^{\mathrm{s}} \mathrm{t}$ century. Atmospheric Environment, 43, 3520-3537 (2009).

DOI: $10.1016 /$ j.atmosenv.2009.04.024

[6] Takeda K., Takeda A. L., Bryant J., Clegg A. C.: Systematic review of the impact of emissions from aviation on current and future climate. The Aeronautical Journal, 112, 493-522 (2008).

[7] Dreyer L. C., Niemann A. L., Hauschild M. Z.: Comparison of three different LCIA methods: EDIP97, CML2001 and Eco-indicator 99. Does it matter which one you choose? The International Journal of Life Cycle Assessment, 8, 191-200 (2003). DOI: $10.1007 / \mathrm{BF} 02978471$

[8] Soutis C.: Fibre reinforced composites in aircraft construction. Progress in Aerospace Sciences, 41, 143151 (2005).

DOI: $10.1016 /$ j.paerosci.2005.02.004

[9] Aeronautics and transport: Beyond vision 2020 (towards 2050). Advisory Council for Aeronautics Research in Europe, Brussels (2010).

[10] Aviation Legal Eye - Spring 2010. Stephenson Harwood, London (2010).

[11] Campbell F. C.: Manufacturing technology for aerospace structural materials. Elsevier, Amsterdam (2006).

[12] The aircraft at end of life sector: A preliminary study. Engineering and Physical Sciences Research Council, Swindon (2007). 
[13] Beck A. J., Hodzic A., Soutis C., Wilson C. W.: Lifecycle assessment to optimise aerospace composites. in 'The $10^{\text {th }}$ International Conference on Deformation and Fracture of Composites, Sheffield, UK' p.19 (2009).

[14] Eco-indicator 99 manual for designers: A damage oriented method for life cycle impact assessment. Ministry of Housing, Spatial Planning and the Environment, Hague (2000).

[15] Campbell F. C.: Manufacturing processes for advanced composites. Elsevier, Amserdam (2004).
[16] Leroy C.: Provision of LCI data in the European aluminium industry: Methods and examples. The International Journal of Life Cycle Assessment, 14, S10-S44 (2009).

DOI: $10.1007 / \mathrm{s} 11367-009-0068-6$

[17] Vlot A., Gunnik J. W.: Fibre metal laminates: An introduction. Kluwer, Dodrecht (2001).

[18] Nuic A.: User manual for the base of aircraft data (BADA). Revision 3.6. EUROCONTROL Experimental Centre, Bretigny-sur-Orge (2004).

[19] Peel C. J., Gregson P. J.: Design requirements for aerospace structural material. in 'High performance materials in aerospace' (ed.: Flower H. M.) Chapman and Hall, London, 1-48 (1995). 